\title{
Strength determination of wagon bearing structures made of round pipes at railroad ferry transportation
}

\author{
Oleksij Fomin $^{1}$, Alyona Lovska ${ }^{2}$, Václav Píštěk ${ }^{3}$, Pavel Kučera ${ }^{4}$ \\ ${ }^{1}$ State University of Infrastructure and Technologies, Kyrylivska str., 9, 04071, Kyiv, Ukraine \\ ${ }^{2}$ Ukrainian State University of Railway Transport, Feierbakh sq., 7, 61050, Kharkiv, Ukraine \\ ${ }^{3,4}$ Brno University of Technology, Technická 2896/2, 616 69, Brno, Czech Republic \\ ${ }^{2}$ Corresponding author \\ E-mail: ${ }^{1}$ fominaleksejviktorovic@gmail.com, ${ }^{2}$ alyonalovskaya.vagons@gmail.com, ${ }^{3}$ pistek.v@fme.vutbr.cz, \\ ${ }^{4}$ kucera@fme.vutbr.cz
}

Received 22 September 2019; accepted 29 October 2019

DOI https://doi.org/10.21595/vp.2019.21060

Check for updates

Copyright (C) 2019 Oleksij Fomin, et al. This is an open access article distributed under the Creative Commons Attribution License, which permits unrestricted use, distribution, and reproduction in any medium, provided the original work is properly cited.

\begin{abstract}
The article presents the results of strength simulation of the bearing structure of freight wagon bodies made of round pipes during railway ferry transportation. In order to reduce the cost for manufacturing freight wagons, the introduction of round pipes in the supporting structure was proposed. In order to ensure the possibility of transportation of the designed structures of wagons on railway ferries, it was proposed to install on their draw bars an assembly unit for fixing with regard to decks. The value of the dynamic load which acts on the supporting structures of the bodies of the main types of freight wagons transported on the railway ferry was determined and the strength was calculated. It was established that the maximum equivalent stresses are within admissible values. The obtained results will enhance the efficiency of the operation of freight wagons through international transport corridors.
\end{abstract}

Keywords: freight wagon, bearing structure, dynamic load, strength, railroad ferry.

\section{Introduction}

The increase in the volume of freight traffic between European countries has caused the development and successful operation of combined transport systems. In countries which have access to international traffic through the sea areas, the rail and ferry transportation has been developed. The peculiarity of such transportation is the possibility of the movement of wagons by sea on railway ferries (Fig. 1). The wagons are secured to ensure their stability with respect to decks. Since the construction of wagons does not compose special units for fixing, it is secured to the units which are not intended for this purpose.

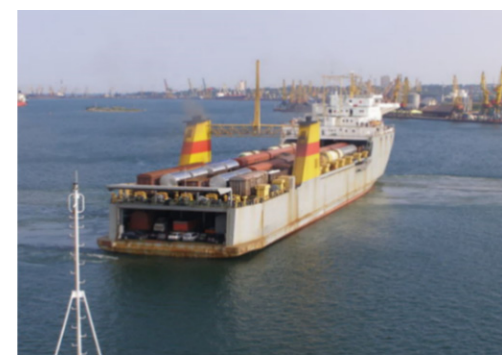

a)

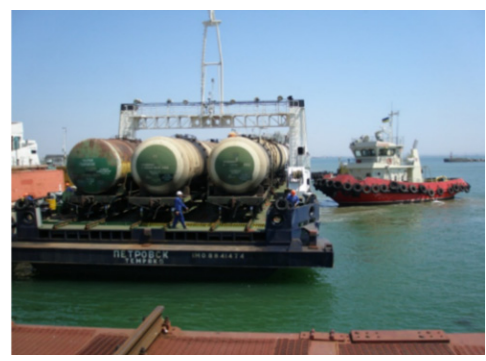

b)

Fig. 1. Railroad ferries with the wagons on board a) "Geroi Odessyi", b) "Petrovsk"

It causes damage of wagons when transported on railway ferries and the need for unscheduled maintenances, and therefore it leads to additional costs. In addition, the disturbance of the stability of the wagon body with regard to the deck can lead to loss of stability of the railway ferry. Therefore, it is necessary to ensure structural adaptation of wagons to the interaction with the means of securing for the reliability of fastening the wagons with regard to the decks of railway ferries. 


\section{Previous research overview}

Results of the theoretical and experimental research of the strength of the Fals series open-top wagon are given in [1]. When carrying out strength calculations, the loads that act on the car during operation on the main tracks were taken into account.

Determination of longitudinal forces acting on the rolling stock when using different types of damping devices in the harnesses of automatic couplings is carried out in [2]. Dynamic load of wagons when transported on railway ferries are not considered in the paper.

The analysis of structural features of the freight wagons BCNHL is carried out in [3]. No attention is paid to improving the scheme of wagon interaction with the railway ferry deck.

The results of previous researches of hot ceramic firing under pressure with alternating current are given in [4].

Research of spatial vibration of freight wagons using the computational model with due consideration of their inertial properties is carried out in [5]. Determination of dynamic load of bearing structures of wagon bodies when transported on railway ferries is not considered.

Determination of the stress-strain state of bearing structures of 12-757 open-top wagons with typical for 1.5 years wear is defined in [6]. It has been established that the maximum equivalent load does not exceed the admissible values, which allows concluding that the wagon can be further used.

Determination of the usefulness of the joined back frame is considered in [7]. The researches have been carried out in theoretical and experimental ways on the example of a hopper wagon. When calculated the strength of the bearing structures of the wagon bodies, the loads applied during transportation on the railway ferry were not taken into consideration.

Features of the modernization of freight wagons during routine maintenance are considered in [8]. Within the framework of the project, it is proposed to manufacture a body of the wagon from composite panels and to paint with anticorrosive materials.

Other methods for dynamic analysis of mechanical structures, including examples of their application, are described in $[9,10]$.

\section{Computational model creation}

The aim of the research was to identify special features of determining strength of bearing structures of the wagons made of round pipes when transported on railway ferries. In order to the aim, the following tasks have been set:

- to improve the bearing structures of wagons for the transportation on railway ferries;

- to determine the dynamic loading of bearing structures of wagons when transported on a railway ferry;

- to calculate the strength of bearing structures of wagons when transported on railway ferries.

In order to increase the efficiency of the operation of railway wagons, it was proposed to use round pipes as supporting members of wagon bodies (Figs. 2-4). Such engineering solution will reduce the cost of manufacturing new wagons at wagon manufacturing plants under conditions of strength and operational reliability [11].

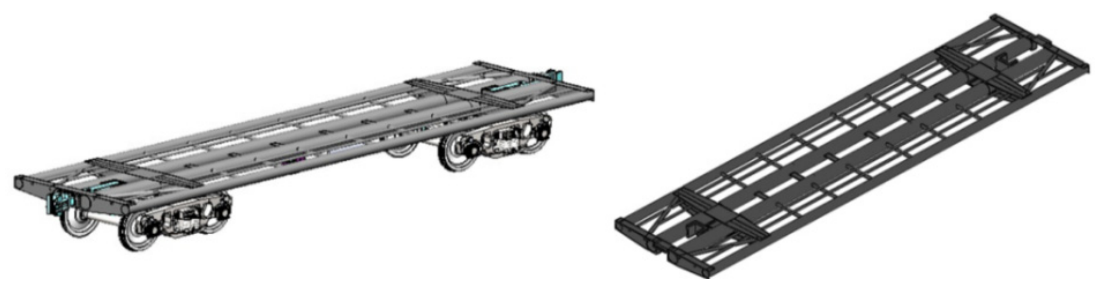

Fig. 2. Computer models of railway wagons whose bearing elements of bodies are made of round cross-section pipes: flat wagon 

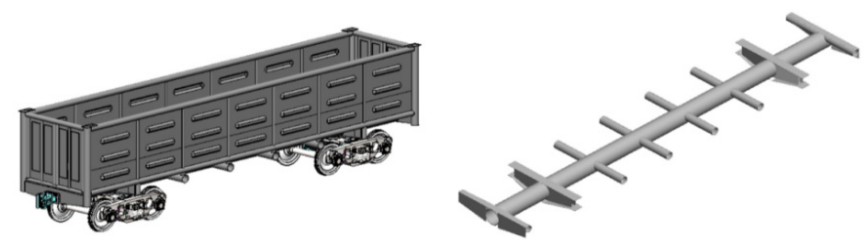

Fig. 3. Computer models of railway wagons whose bearing elements of bodies are made of round cross-section pipes: open-top wagon
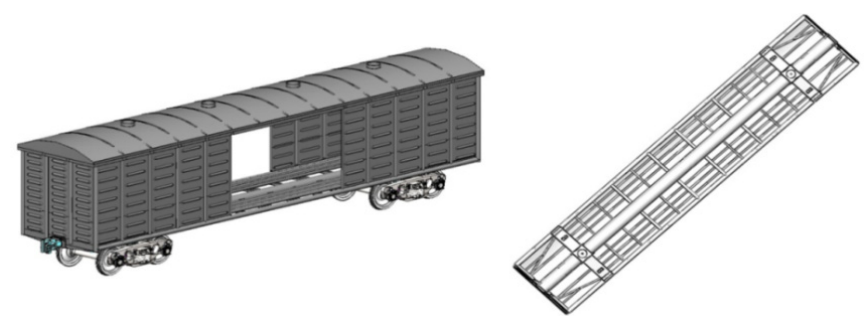

Fig. 4. Computer models of railway wagons whose bearing elements of bodies are made of round cross-section pipes: covered wagon

For the possibility of transportation of designed structures of wagons on railway ferries, it was proposed to equip their constructions with assembling units for fixing with regard to the decks (Fig. 5).

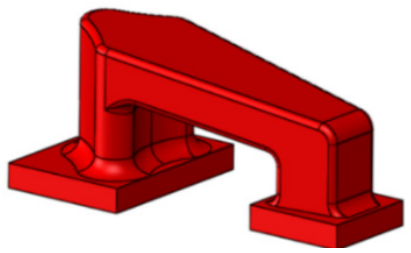

a)

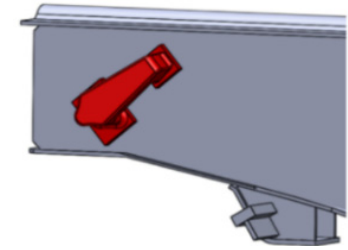

b)

Fig. 5. A node for wagon fastening to the deck of the railway ferry

a) general view; b) allocation on the draw bar

At the initial research stage the dynamic loading of bearing structures of wagon bodies made of round pipes was investigated to determine the strength of bearing structures when transported on the railway ferry. The mathematical model presented in [12] was used:

$$
\left(\left(\frac{D}{12 g}\left(B^{2}+4 z_{g}^{2}\right)\right) \ddot{q}+\left(\Lambda_{\theta} \frac{B}{2}\right) \dot{q}=p^{\prime} \frac{h}{2}+\Lambda_{\theta} \frac{B}{2} F(t) p-p_{a}\right),
$$

where $q=\theta$ is the generalized coordinate which corresponds to the angular displacement of a railway ferry with wagons on board around the longitudinal axis. The coordinate system origin is at the centre of mass of a railway ferry; $D$ is weight displacement, $B$ is the width of the railway ferry, $h$ is the hull height of the railway ferry, $\Lambda_{\theta}$ is the coefficient of resistance to motions, $z_{g}-$ coordinate of the gravity centre of a railway ferry, $p^{\prime}$ - wind load, $F(t)$ is the force time waveform that causes the movement of a railway ferry with wagon bodies on its decks.

The research has been conducted relating to the ferry "Geroi Shipki", which moves along the Black Sea water area. The model takes into account the angular movements of the railway ferry with the wagons placed on it at angular movements around the longitudinal axis (heel).

This type of moving process has been taken into account because it causes the greatest impact on the stability of the vessel under conditions of sea disturbance $[13,14]$, and therefore on the 
wagons placed on it. It has been taken into consideration the fact that the wagon body is fixed rigidly with respect to the deck and moves along with it.

The differential equation of motion Eq. (1) was solved applying the programming environment Mathcad $[15,16]$ by using the Runge-Kutta method. Initial displacement and velocity are taken as zero [17]. It was established that the maximum acceleration value as a component of the dynamic loading acting on a wagon is about $0.24 \mathrm{~g}$. The obtained value of the dynamic load was taken into account when calculating the strength of the bodies of the main wagon types that are transported by rail ferries. The calculation is based on the finite element method implemented in the CosmosWorks programming environment [18].

The strength models of bearing structures of wagons bodies when transported on a railway ferry are shown on Figs. 6-8. In the preparation of FEM models of wagon bodies, ten-node isoparametric tetrahedra were used. The optimal number of grid elements was determined by the graphic-analytical method.

The models take into consideration the vertical-static load $P_{v}^{s t}$, the load acting through the chain link $P_{c h . l}$, as well as the wind load $P_{v}$. When constructing the model of the strength of an open-top wagon, the outward pressure of dry bulk cargo was taken into consideration $P_{p}$ (hardcoal). In the models of the strength of the flat wagons and the body of the covered wagon, it has been taken into consideration the fact that they are loaded with a conventional cargo, using full load-carrying capacity. Since the chain ties, which fasten the bodies of wagons with regard to the decks, have a spatial arrangement, then the force transmitted through them was decomposed into components, considering the angles of placement of the ties in interspace.

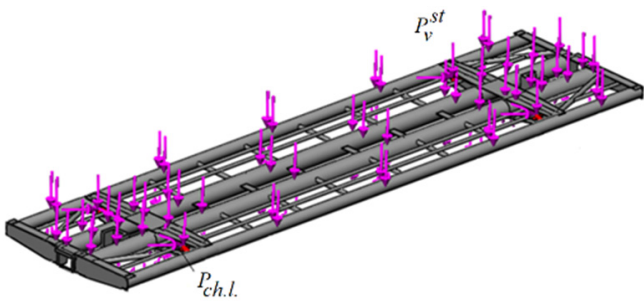

Fig. 6. Models of strength of wagon bodies made of round pipes when transported on a railway ferry: flat wagon

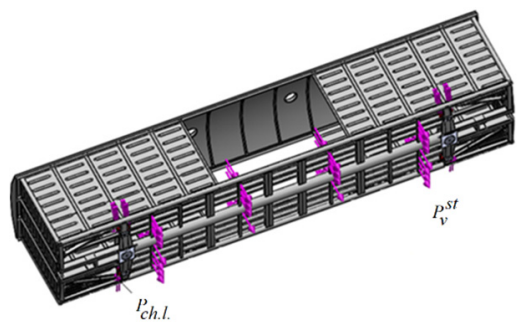

Fig. 8. Models of strength of wagon bodies made of round pipes when transported on the railway ferry: covered wagon

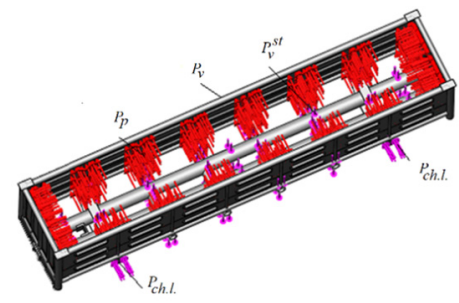

Fig. 7. Models of strength of wagon bodies made of round pipes when transported on a railway ferry: open-top wagon

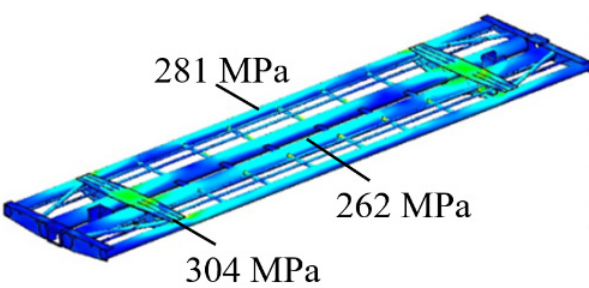

Fig. 9. Stress state of the bearing structure of the flat wagon when transported on the railway ferry

Fastening of models was carried out in the zones of their support on the bogies, as well as on the bearing surfaces of mechanical jack installations. 09G2S steel was used as a material of bearing structures. The main calculation results in quasi-statics are shown in Figs. 9-11.

The calculations have shown that the maximum equivalent stresses in the bearing structure of the flat wagon arise in the zones of interaction of the draw bars with the back frame and amount to about $280 \mathrm{MPa}$ (Fig. 9), i.e. they do not exceed the admissible values [19-21]. Maximum displacements arise in the middle part of the main longitudinal beam of the frame where chain ties 
are located and which are stretched at the angular displacement of the bearing structure of the flat wagon, and amount to $27.7 \mathrm{~mm}$.

The maximum equivalent stresses in the open-top wagon structure arise in the middle part of the frame and amount about $260 \mathrm{MPa}$, i.e. they do not exceed the admissible values (Fig. 10). Maximum displacements arise in the middle part of the side wall of the body of the open-top wagon from its tilt at the roll and amount to $15.6 \mathrm{~mm}$.

The maximum equivalent stresses in the bearing structure of the covered wagon body arise in the zones of the interaction of the draw bars with the back frame and are about $280 \mathrm{MPa}$, i.e. they do not exceed the admissible values (Fig. 11). The maximum displacements arise in the middle part of the main longitudinal beam of the frame from the side of placing the chain ties, which are stretched at the angular displacement of the wagon structure and amount to $25.4 \mathrm{~mm}$.

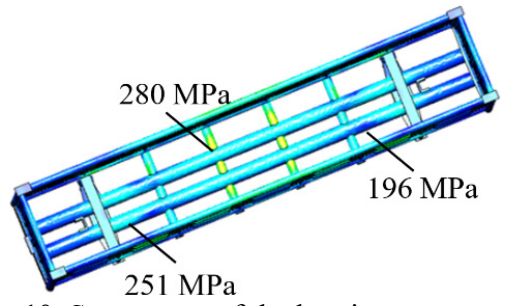

Fig. 10. Stress state of the bearing structure of the open-top wagon body when transported on the railway ferry

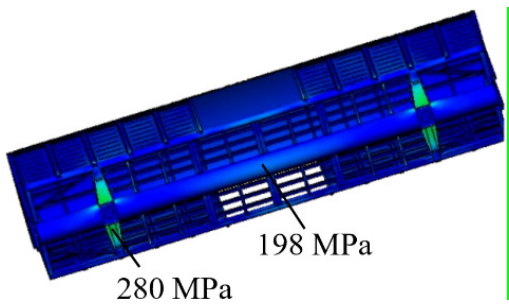

Fig. 11. Stress state of the bearing structure of the covered wagon body when transported on the railway ferry

\section{Conclusions}

Bearing structures of the main types of freight wagons for the transportation on railway ferries have been improved. The dynamic load of bearing structures of the main types of freight wagons when transported on a railway ferry has been determined. Attention was taken to the angular movements of the ferry with wagons, located with regard to the decks. It was established that the maximum acceleration acting on the body of the wagon considering the meteorological conditions of the Black Sea is $0.24 \mathrm{~g}$.

Maximum equivalent stresses on the body of wagons have been determined. Furthermore, the maximum equivalent stresses in the wagon bodies are within the admissible limits considering the proposed technical solutions. It should be noted that earlier issues of creating wagons that are adapted for safe transportation on railway ferries did not receive due attention. The research results will improve technical parameters of bearing structures of the basic types bodies of freight wagons carried on railway ferries, and also increase the efficiency of their operation in the international connection.

\section{Acknowledgements}

This work displays the results of international inter-university research and is also an output of the internal BUT research project Reg. No. FSI-S-17-4104.

\section{References}

[1] Slavchev S., Georgieva K., Stoilov V., Purgic S. Analysis of the results of theoretical and experimental studies of freight wagon falls. Facta Universitatis, Series: Mechanical Engineering, Vol. 13, Issue 2, 2015, p. 91-98.

[2] Utsab R., Bidhan M., Binoy K. R. Study on longitudinal forces of a freight train for different types of wagon connectors. IFAC PapersOnLine, Vol. 51, Issue 1, 2018, p. 283-288.

[3] Chandra P. S., Bharti P. K. Study and analysis of doors of BCNHL wagons. International Journal of Engineering Research and Technology, Vol. 4, Issue 4, 2015, p. 1195-1200. 
[4] Gevorkyan E., Lavrynenko S., Rucki M., Siemiatkowski Z., Kislitsa M. Ceramic cutting tools out of nanostructured refractory compounds. International Journal of Refractory Metals and Hard Materials, Vol. 68, 2017, p. 142-144.

[5] Myamlin S., Neduzha L., Ten O., Shvets A. Spatial vibration of cargo cars in computer modelling with the account of their inertia properties. Proceedings of the 15th International Conference, Mechanika, 2010.

[6] Fomin O., Gerlici J., Lovskaya A., Kravchenko K., Prokopenko P., Fomina A., Hauser V. Research of the strength of the bearing structure of the flat wagon body from round pipes during transportation on the railway ferry. MATEC Web of Conferences, Vol. 235, 2018, p. 00003.

[7] Fomin O., Logvinenko O., Burlutsky O., Rybin A. Scientific substantiation of thermal levelling for deformations in the car structure. International Journal of Engineering and Technology, Vol. 7, Issues 4-3, 2018, p. 125-129.

[8] Płaczek M., Wróbel A., Buchacz A. A concept of technology for freight wagons modernization. IOP Conference Series: Materials Science and Engineering, Vol. 161, 2016, p. 012107.

[9] Zajac R., Rehák K., Prokop A. Investigation of the harmonic response on the simple structure in structural and acoustic domain by experimental and numerical approach. Transport Means, 2018, p. 669-672.

[10] Zajac R., Prokop A., Řehák K. Determination of the modal parameters on the thin flat structures. Vibroengineering Procedia, Vol. 18, 2018, p. 91-95.

[11] Fomin O., Lovska A., Masliyev V., Tsymbaliuk A., Burlutski O. Determining strength indicators for the bearing structure of a covered wagon's body made from round pipes when transported by a railroad ferry. Eastern-European Journal of Enterprise Technologies, Vol. 1, Issues 7, 2019, p. 33-40.

[12] Lovska A. Simulation of loads on the carrying structure of an articulated flat car in combined transportation. International Journal of Engineering and Technology, Vol. 7, Issues 4-3, 2018, p. 140-146.

[13] Blagoveshchensky S. N., Kholodilin A. N. A Reference Book on the Statics and Dynamics of a Ship. Shipbuilding, Leningrad, 1975, p. 176, (in Russian).

[14] Makov Yu. L. Pumping of Ships. KSTU, Kaliningrad, 2007, p. 321, (in Russian).

[15] Kiryanov D. V. Mathcad 13. St. BHV, Petersburg, 2006, p. 528, (in Russian).

[16] Fomin O., Gerlici J., Lovska A., Kravchenko K., Prokopenko P., Fomina A., Hauser V. Durability determination of the bearing structure of an open freight wagon body made from round pipes during its transportation on the railway ferry. Communications-Scientific letters of the University of Zilina, Vol. 21, Issue 1, 2019, p. 28-34.

[17] Kondratiev A. V., Gaigachuk V. E., Kharchenko M. E. Relationships between the ultimate strengths of polymer composites in static bending, compression, and tension. Mechanics of Composite Materials, Vol. 52, Issue 2, 2019, p. 259-266.

[18] Alyamovsky A. A. SolidWorks/COSMOSWorks 2006-2007 - Engineering Analysis by the Finite Element Method. Moscow, DMK, 2007, p. 784, (in Russian).

[19] Freight Wagons. General Requirements for the Calculations and Design of New and Upgraded 1520 mm (non-self-propelled) Railcars. DSTU 7598: 2014, 2014, p. 162, (in Ukrainian).

[20] Freight Wagons. Strength and Dynamic Quality Requirements. GOST 33211-2014, 2014, p. 54, (in Russian).

[21] Railway Applications - Structural Requirements of Railway Vehicle Bodies. Part 2. Freight Wagons. EN 12663-2, p. 54. 